\title{
Correction to: Complete genome sequence of a phage hyperparasite of Candidatus Xenohaliotis californiensis (Rickettsiales) - a pathogen of Haliotis spp (Gasteropoda)
}

\author{
Roberto Cruz-Flores ${ }^{1}$. Jorge Cáceres-Martínez ${ }^{1,2}$ (D) Miguel Ángel Del Río-Portilla ${ }^{1}$ - Alexei F. Licea-Navarro ${ }^{1}$. \\ Ricardo Gonzales-Sánchez ${ }^{1} \cdot$ Abraham Guerrero $^{1}$
}

Published online: 5 February 2018

(c) Springer-Verlag GmbH Austria, part of Springer Nature 2018

\section{Correction to: Archives of Virology \\ https://doi.org/10.1007/s00705-018-3703-3}

Unfortunately, the family name of the co-author Roberto Cruz-Flores was incorrectly published in the original publication and corrected here by this correction. The original article has been corrected.

1 Centro de Investigación Científica y de Educación Superior de Ensenada (CICESE), Carretera Ensenada-Tijuana No. 3918, Zona Playitas, 22860 Ensenada, Baja California, México

2 Instituto de Sanidad Acuícola, A.C. (ISA), Calle de la Marina S/N. esq. Caracoles, Fracc. Playa Ensenada, 22880 Ensenada, Baja California, México 